Normand Tremblay MD, Jean Taillefer MD, Jean-François Hardy MD

\title{
Successful non-surgical extraction of a knotted pulmonary artery catheter trapped in the right ventricle
}

A patient is presented in whom a pulmonary artery catheter (PAC) formed a knot which was fixed in the region of the tricuspid valve chordea. The PAC was successfully and nonsurgically freed from its attachment and removed. A guide wire was introduced by the distal port of the PAC and under fluoroscopy the PAC was manipulated free and then extracted easily.

On rapporte un malade chez qui un noeud s'est formé sur un cathéter d'artère pulmonaire (CAP) et qui était fixé à l'appareil tricuspidien. De façon non invasive le CAP fut libéré et retiré avec succès. On a introduit un guide métallique dans la voie distale du CAP et, en le manipulant sous fluoroscopie, on a réussi à libérer et à extraire le cathéter.

Among the many complications associated with pulmonary artery catheters (PAC) is knot formation. This problem is usually easily dealt with by simply withdrawing the PAC until the knot impacts onto the introducer and after enlarging the puncture site by a small skin incision removing the introducer-PAC as one unit.

However, we recently encountered a situation where the knotted PAC appeared to be fixed within the heart and could not be withdrawn. Since we managed in successfully removing the PAC nonsurgically we thought our experience could be of use to others.

\section{Key words}

EQUIPMENT: catheter, pulmonary arterial; COMPLICATIONS: accidents.

From the Département d'Anesthésie-Réanimation, Institut de Cardiologie de Montréal, 5000, rue Bélanger est, Montréal, Quebec, H1T 1C8.

Address correspondence to: Dr. Normand Tremblay, Institut de Cardiologie de Montréal, 5000, rue Bélanger est, Montréal, Québec, H1T 1C8.

Accepted for publication 28th October, 1991.

\section{Case report}

A 57-yr-old woman recently presented for elective coronary revascularization. She had a 50\% left main coronary artery stenosis, an occluded right coronary artery and left ventricular function was normal. Except for obesity (weight $=75 \mathrm{~kg}$ and height $=150 \mathrm{~cm}$ ), she had no other disease and her angina was well controlled with metoprolol. All preoperative laboratory studies, including chest $x$-ray, were normal.

Upon arrival in the operating room (OR), routine monitoring was installed while sedated, breathing oxygen delivered by nasal canula. A PentaPace QRS 7.5 F flowdirected thermodilution catheter (Viggo-Spectramed, Oxnard, CA) was easily inserted (a single successful attempt) through an 8.5 F Arrow-Flex Radiopaque Sheath (Arrow International Inc., Reading, PA) in the right internal jugular vein (IJV). The pulmonary artery pressure (PAP) was $27 / 12 \mathrm{mmHg}$ and the wedge pressure was 11 $\mathrm{mmHg}$. However, the PAC had to be inserted to $65 \mathrm{~cm}$ at the hub of the introducer before wedging, an unusually long distance considering the patient's height. According to routine procedure, before initiation of cardiopulmonary bypass (CPB) the PAC was withdrawn $2-3 \mathrm{~cm}$. The distal tip of the PAC was now in the right ventricle (RV), as shown by the distal port pressure tracing and by the accompanying multiple ventricular ectopic beats. The PAC was withdrawn to $30 \mathrm{~cm}$ and repositioned in the PA artery at a distance of approximately $45 \mathrm{~cm}$ from the hub of the introducer before wedging (a distance more in line with the patient's stature).

Surgery consisted of right and left internal mammary artery and saphenous vein grafts. The surgeon judged the quality of the revascularization to be suboptimal. Weaning from CPB required pharmacological intervention. The PAP decreased from $60 / 40$ to $50 / 30 \mathrm{mmHg}$ and a wedge pressure could not be obtained.

Chest $x$-rays (CXR), within $90 \mathrm{~min}$ of arrival in the postoperative intensive care unit, showed the tip of the PAC to be in the RV outflow tract and a knot in the PAC approximately $5 \mathrm{~cm}$ from its distal end and situated in the 


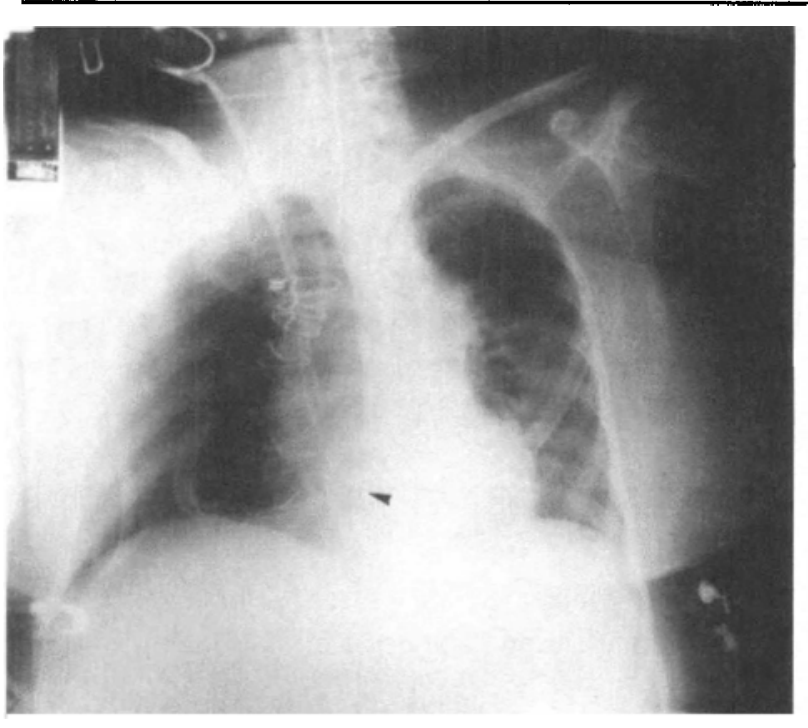

FIGURE 1 Left anterior oblique view of a chest $x$-ray showing the knot (arrow) in the PAC fixed in the tricuspid chordea while a gentle traction is applied to the catheter.

RV. An attempt was made to withdraw the PAC but at the $30 \mathrm{~cm}$ mark it offered resistance. A second CXR obtained while maintaining the PA catheter taut by gentle traction showed the knot to be "fixed" in the vicinity of the tricuspid valve and this was confirmed by an oblique CXR (Figure 1).

After discussion among interventional cardiologists, radiologists, surgeons and ourselves, the consensus was that the PAC was most likely caught or wedged in tricuspid chordea. Since the patient was still under the effect of residual anaesthesia and since there was a strong possibility that removal of the PAC would require surgical intervention (i.e., atriotomy using $\mathrm{CPB}$ ) we agreed to forego fluoroscopic manipulations at the bedside or in the catheter laboratory. Rather, it was decided that such an attempt should be tried in the OR where surgery could be carried out in case of failure.

The patient was brought back to the $O R$. Using fluoroscopy we found that the knot did not appear to be too tight and we proceeded to attempt to undo it by rendering the PAC more rigid with a guide wire. While one of us passed a 0.025 in diam wire (145 cm long) (USCI C.R., Bard Galway, Ireland) through the distal port of the catheter, the other pushed then pulled the PAC gently. Passage of the guide wire arrested at the knot and although the knot could not be undone, the PAC eventually could be seen to become free from the tricuspid valve apparatus. The PAC yielded to gentle traction and was easily withdrawn until the knot impacted onto the introducer. Both the introducer and the knotted PAC

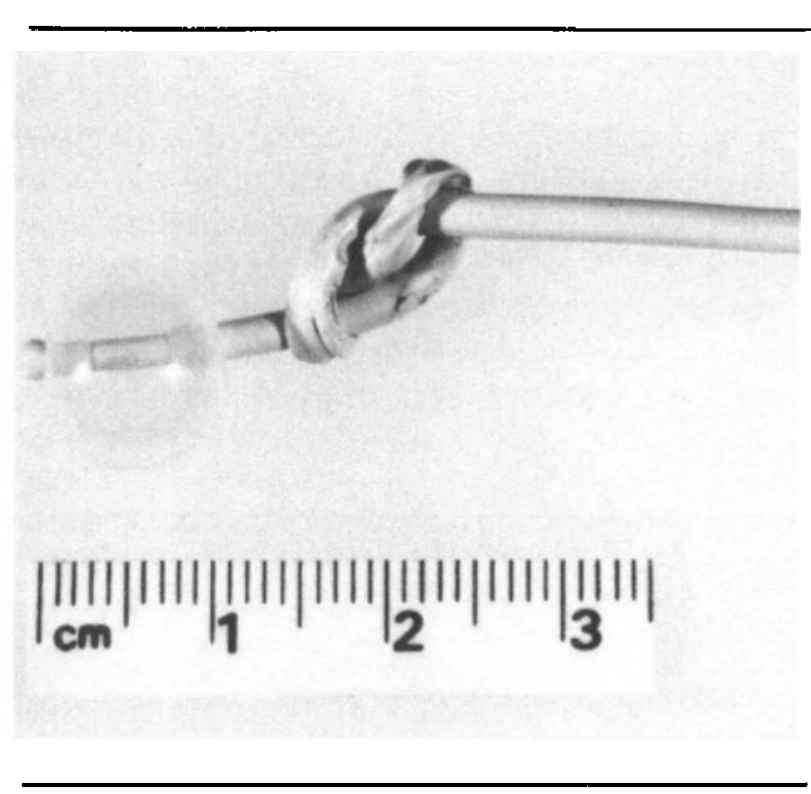

FIGURE 2 Knot in the removed PAC. Balloon inflated to show the relative size of the knot after extraction.

(Figure 2) were removed up to the knot which then was extracted following a small skin incision. The balloon was intact and deflated.

\section{Discussion}

The problems (and their solutions) associated with flowdirected PACs are varied. In addition to the problems generally related to central venous access, there are frequent specific difficulties related to the use of a flowdirected PAC (dysthythmias, loops and abnormal positioning) and less frequent ones such as: catheter defects, ${ }^{1,2}$ faulty use of catheters, ${ }^{3}$ extracardiac pathology affecting catheter use, ${ }^{4,5}$ unusual catheter positions, ${ }^{6,7}$ and vascular perforation. 8

We encountered a situation where a knotted PAC was entrapped in the heart and where we succeeded in removing it nonsurgically. Under fluoroscopic examination, gentle to-and-fro movement of the catheter (rendered stiff with the help of a guide wire) made it possible to dislodge the knot from the chordae of the tricuspid valve where we believed it was trapped.

Gentle manipulation was essential since it was impossible to exclude the possibility that the catheter might be knotted around a valvular chorda. If this had occurred, excessive traction on the knotted PAC could have led to rupture of the chorda. Cautious manipulation of the PAC and the clinical evolution of the patient after the procedure excluded this possibility.

Other possible manoeuvres could have been done under fluoroscopy. The introducer sheath could be replaced with 
a long $(59 \mathrm{~cm})$ Mullins $8.0 \mathrm{Fr}$ Transeptal Catheter Introducer (USCI, Belerica, CA) advanced to include the knot within the introducer and withdrawing both together. Curry ${ }^{10}$ described an approach using a separate puncture site (i.e., femoral vein), and a snare loop formed by folding in half a long $(260 \mathrm{~cm}) 0.035$ in teflon-coated catheter exchanger (Cook, Bloomington, IN) passed through a Mullins introducer, to lasso the knot free. Also, a Bioptome (Cordis, Miami, FL) used for endomyocardial biopsies can be introduced via a separate approach (femoral vein) and attempts made to grab and dislodge the knot.

This is the first time that we have seen this complication in our department where anaesthetists have inserted over 15,000 PACs since 1977. We consider ourselves fortunate to have been able to manoeuvre and extract the PAC without resorting to surgery and CPB. Occasionally interventional cardiologists and radiologists do remove foreign bodies (i.e., catheters, guide wires or parts thereof) from cardiac chambers using the above techniques.

Although the occurrence of knots in PACs is rare, it is known that advancing the catheter too far predisposes to knot formation. In the general adult population, it is recommended that a PAC should not be passed more than $50 \mathrm{~cm}$ using the internal jugular vein approach. Strict adherence to this recommendation should prevent the recurrence of such mishaps.

\section{Acknowledgements}

The authors wish to thank Drs. Raoul Bonan, Gilles Hudon and Jean-Paul Martineau for the helpful advice and cooperation and Mrs Mary Morello for her expert secretarial assistance.

\section{References}

1 Suderman V, Crosby E. Pulmonary artery catheter failure. Can J Anaesth 1990; 37: 388-9.

2 Higgins CM, Lake CL, Ross WT. The "Shunting" SwanGanz catheter, in Case 1989-2. Journal of Cardiothoracic and Vascular Anesthesia 1989; 3: 229-34.

3 Meluch AM, Karis JH. Obstruction of venous return by a pulmonary artery catheter during cardiopulmonary bypass. Anesth Analg 1990; 70: 121 (letter).

$4 \mathrm{Y}$ U PHY, Lee $L W$. Pulmonary artery pressures with tension pneumothorax. Can J Anaesth 1990; 37: 584-6.

5 Brown PJ. An unusual cause of inability to float a pulmonary artery catheter. Journal of Cardiothoracic and Vascular Anesthesia 1989; 3: 333-6.

6 Allyn J, Lichenstein A, Koski EG, Jacobs ML, Lowenstein $E$. Inadvertent passage of a pulmonary artery catheter from the superior vena cava through the left atrium and left ventricle into the aorta. Anesthesiology 1989; 70: 1019-21.
7 Johnson WE, Royster RL, Choplin RH, Howard G, Mills $S A, T u c k e r$ WY. Pulmonary artery catheter migration during cardiac surgery. Anesthesiology 1986; 64: 258-62.

8 Barash $P G$, Nardi D, Hammond $G$ et al. Catheter induced pulmonary artery perforation: mechanisms, management and modifications. J Thorac Cardiovasc Surg 1981; 82: 5-12.

9 Hardy JF, Morissette M, Taillefer J et al. Pathophysiology of rupture of the pulmonary artery by pulmonary artery balloon-tipped catheters. Anesth Analg 1983; 62: 925-30.

10 Curry JL. Retrieval of detached intravascular catheter or guide fragments - a proposed method. American Journal of Radiology 1969; 105: 894-6. 